\title{
Management of immigration and pregnancy screening in northeastern Italy
}

\author{
This article was published in the following Dove Press journal: \\ Risk Management and Healthcare Policy \\ 20 January $201 \mathrm{I}$ \\ Number of times this article has been viewed
}

\section{Giorgio Tamaro \\ Sergio Parco}

Department of Laboratory Medicine, Children's Hospital, Burlo Garofolo, Trieste, Italy
Correspondence: Sergio Parco Children's Hospital, Burlo Garofolo, Via dell'Istria 65/I, 34I37, Trieste, Italy Tel +34760 l 0086

$\mathrm{Fax}+390403785210$

Email parco@burlo.trieste.it

\begin{abstract}
This study assesses the impact of immigration in Friuli Venezia Giulia, a region of northeastern Italy, on the epidemiological features of hemoglobin patterns and on prothrombotic and trisomy risk in pregnancy for patients of non-Italian origin. This study follows a series of studies on the incidence of thalassemia and other hemoglobinopathies with reduced globin chain synthesis, that were performed during the postwar (1939-45) period in Friuli Venezia Giulia following immigration into the region from Istria and Sardinia (regions of northern and central Italy). Current data show that today's constantly growing immigration into the region differs from previous decades, in terms of origin and quantity of migrants, who mainly come from third world countries. This has a significant impact on health care issues, and more specifically on prospective health screening for foreigners. The authors conclude that scholastic education and hospital services, either public or private, and voluntary associations, may contribute to solving the problem, but only in terms of training and organization, for non-European Union citizens arriving in northern Italy and neighboring areas, especially those from Africa, Asia, Latin America, and eastern Europe.
\end{abstract}

Keywords: immigration, hemoglobinopathy, pregnancy, trisomy, thalassemia trait, Italy

\section{Introduction}

Immigration percentages in Friuli Venezia Giulia (FVG), a region with 1,200,000 inhabitants and located in northeastern Italy, in the first decade of the millennium were compared with data from other Italian regions over the same period, such as Latium, where immigrants accounted for $7.5 \%$ of total inhabitants, or Piedmont where $2.6 \%$ of university students were foreigners. The data were provided by the Italian Institute of Statistics. The comparison showed that FVG values were higher than the national average (1.6\%). In particular, the main town of Trieste accounted for approximately $4.5 \%$ of regional immigration. The current FVG data are even more marked, and indicate a constantly growing influx of immigrants who, to date, account for $7.7 \%$ of residents in the region. ${ }^{1}$ This immigration pattern has greater health care implications than in the past.

For instance, in the past, the provinces of Trieste and FVG were never typically affected by thalassemia. In the 1950s and 1960s, following immigration from areas with a high incidence of thalassemia and other hemoglobinopathies, such as Istria and Sardinia, the trait frequency first soared and later plummeted. Today, immigration from African and Asian countries into Italy has contributed to the further diffusion of thalassemia and sickle cell disease, causing increased health care problems, particularly 
with regard to blood transfusions in non-European Union patients affected by these diseases. ${ }^{2}$

Another example is the biochemical screening for Down syndrome, Edwards syndrome, fetal open neural tube defects, and spina bifida, a health care issue that requires renewed attention in light of the new immigration trends and the frequent difficulties of communication and health care delivery. In Italy, an increased proportion of the population has been resorting to these screening tests because of the availability of more accurate amniocentesis for detection of structural fetal anomalies. In Piedmont, for example, about 197,000 pregnancies were evaluated by one laboratory between 1990 and 2007, and the questionnaire provided to mothers by the Piedmont health care institutions required an indication of the patient's country of origin. Knowledge of the native country is relevant because the median of the risk calculation differs between African, Asian, and Caucasian individuals. Consequently, and importantly, every laboratory should calculate the risk of malformations by using medians obtained from the local and the foreign population, because Asian and African women have higher levels of alpha fetoprotein and the presence of a percentage of non-Caucasian women raises the median maternal serum alpha fetoprotein level. ${ }^{3}$

The aim of this work was to assess the impact of immigration from third world countries on epidemiological patterns in FVG, a region of northeastern Italy and an important gateway to Europe, and also to raise awareness and provide orientation for education on screening and identification of risk factors for transfusion problems in hemoglobinopathies (as alloimmunization of patients with sickle cell disease or thalassemia or thrombosis with abortion by antiphospholipid antibodies) and neonatal complications associated with abnormal maternal serum marker analysis (as free beta human chorionic gonadotropin hormone and protein A to diagnose Down and Edwards syndromes). Indeed, the genetic characteristics of Afro-Asians and eastern Europeans differ from locals for some pathologies, and it is difficult to study these problems in people with a limited grasp of the language and also because of economic difficulties and sanitary problems. The screenings are less expensive when carried out during pregnancy. Hospitals, voluntary associations and public schools are greatly engaged to study hemoglobinopathies and risk factors for other fetal defects.

\section{Materials and methods}

Between January and December 2009 we reviewed diseases detected in subjects undergoing tests for medically assisted
Table I Phoresis of total hemoglobin: normal and pathological plots

\begin{tabular}{lllll}
\hline Year & $\mathbf{1 9 7 5 - 7 6}$ & $\mathbf{1 9 8 6 - 8 7}$ & $\mathbf{1 9 9 5 - 9 6}$ & $\mathbf{2 0 0 9}$ \\
\hline Normal Hb & 302 & 439 & 382 & 516 \\
& $(59.92 \%)$ & $(78.96 \%)$ & $(76.40 \%)$ & $(66.93 \%)$ \\
Pathological Hb & 202 & 117 & 118 & 258 \\
& $(40.08 \%)$ & $(21.04 \%)$ & $(23.60 \%)$ & $(33.07 \%)$ \\
Total & 504 & 556 & 500 & 774 \\
\hline
\end{tabular}

Abbreviation: $\mathrm{Hb}$, hemoglobin.

reproduction at the Children's Hospital, Burlo Garofolo, Trieste, where pregnant women from FVG are checked during pregnancy. The tests included hemoglobin patterns and the risk estimation for miscarriage, Down syndrome (T21), and Edwards syndrome (T18) in single and multiple pregnancies. We studied 774 pregnant women aged 37 years and older during gestational weeks 12 and 14 and undergoing prenatal ultrasonography at the prenatal diagnosis unit in our hospital, who consented to undergo combined biochemical screening because maternal age is an important risk factor for neonatal malformation.

All patients had to sign the informed consent form before entering the study, and enter the place of birth of the baby and its parent/s. According to the result section a patient questionnaire has been used.

Hemoglobin was analyzed using high-pressure liquid chromatography (with reference values for fetal hemoglobin $\geq 1.5 \%$ and hemoglobin $\mathrm{A}_{2} \geq 3.2 \%$ ). The blood count was performed using XE 2100 Dasit and ADVIA 120 Siemens analyzers. These data were compared with those from previous decades (1970-2000), during which hemoglobin patterns had been analyzed by electrophoresis (Helena Rep system with agarose gel), and using Hemalog 8/90, Technicon, and H1 Bayer analyzers for blood counts (reference values for mean corpuscular volume, M 80-94, F 81-99).

The so-called pregnancy-associated combined test (bi-test) and prothrombotic risk factor test were performed

Table 2 Total figures and percentages of minor and major thalassemia

\begin{tabular}{lllll}
\hline Year & $\mathbf{1 9 7 5 - 7 6}$ & $\mathbf{1 9 8 6 - 8 7}$ & $\mathbf{1 9 9 5 - 9 6}$ & $\mathbf{2 0 0 9}$ \\
\hline Non-thalassemia & 302 & 440 & 385 & 518 \\
phenotype & $(59.92 \%)$ & $(79.13 \%)$ & $(77.00 \%)$ & $(66.93 \%)$ \\
$\mathrm{HbF}>1.5 \%$ & 55 & 34 & 9 & 44 \\
& $(10.91 \%)$ & $(6.12 \%)$ & $(1.80 \%)$ & $(5.68 \%)$ \\
$\mathrm{Hb} \mathrm{A2}>3.2 \%$ & 126 & 64 & 101 & 160 \\
& $(25 \%)$ & $(11.51 \%)$ & $(20.20 \%)$ & $(20.67 \%)$ \\
Thalassemia major & 21 & 18 & 5 & 52 \\
$(\mathrm{HbF}+\mathrm{A} 2)$ & $(4.17 \%)$ & $(3.24 \%)$ & $(1.00 \%)$ & $(6.72 \%)$ \\
Total & 504 & 556 & 500 & 774 \\
\hline
\end{tabular}

Abbreviation: $\mathrm{Hb}$, hemoglobin. 
Table 3 Total figures and percentages of hemoglobin variants S, $\mathrm{C}$, and $\mathrm{E}$

\begin{tabular}{lllll}
\hline Year & $\mathbf{1 9 7 5 - 7 6}$ & $\mathbf{1 9 8 6 - 8 7}$ & $\mathbf{1 9 9 5 - 9 6}$ & $\mathbf{2 0 0 9}$ \\
\hline $\mathrm{HbS}$ & 0 & $2(0.36 \%)$ & $4(0.80 \%)$ & $44(5.68 \%)$ \\
$\mathrm{HbC}$ & 0 & 0 & $2(0.40 \%)$ & $6(0.78 \%)$ \\
$\mathrm{HbE}$ & 0 & 0 & 0 & $2(0.26 \%)$ \\
\hline
\end{tabular}

Abbreviation: $\mathrm{Hb}$, hemoglobin.

using plasma protein A (Perkin Elmer, Milan, Italy), the free beta subunit of human chorionic gonadotropin hormone (Perkin Elmer), and antiphospholipid antibodies (Orgentec, Milan, Italy). Starting from the woman's date of birth, the T21 and T18 risk was first calculated by maternal age using an international software program, and then determined after screening by estimating the risk according to the values of the three markers (fetal nuchal translucency, plasma protein $A$, and the free beta subunit of human chorionic gonadotropin hormone). The risk in dichorionic pregnancies was calculated separately for each fetus and a correction factor for twin pregnancies was applied to the values for biochemical markers expressed as the median of the risk calculation. However, in monochorionic pregnancies, the same risk was attributed to both twins, assigning to both fetuses the highest of the two nuchal translucency values detected and the arithmetic average of the two crown rump length values observed. In this case too, a correction for twin pregnancies was applied to the biochemical markers expressed as the median of the risk calculation. No data were available from 1975 to 2009 for comparison.

\section{Results}

Hemoglobin tests were carried out on 774 patients from the Obstetrics and Gynecology Department at the Children's Hospital in Burlo Garofolo and compared with the results from 1975-1976. Hemoglobin analysis detected the presence of 258 abnormal hemoglobins, comprising 160 cases of minor thalassemia, 52 major thalassemias, and 44-S diseases, as well as different percentages of hemoglobin $\mathrm{C}$ and hemoglobin $\mathrm{E}$. Membership of different ethnic groups, mainly Afro-Asian or eastern European, was confirmed using the patient questionnaire, and suggested the percentage breakdown described in Table 1. Particularly significant was the predominance of subjects from Latin America (see Tables 1-5).

Of the pregnancies studied, all were singleton pregnancies, but five were monochorionic twin pregnancies and 9 were dichorionic twin pregnancies. In 41 of the singleton pregnancies, the combined test revealed a high risk only for trisomy 21. In one case, only an increased risk of trisomy 18 was reported, and two pregnancies were at risk of both diseases. The remaining pregnancies were not at risk of either of these two aneuploids. The test was positive for Down syndrome in $5.3 \%$ of singleton pregnancies and for Edwards syndrome in $0.33 \%$. However, in twin pregnancies, the combined screening test revealed an increased risk of trisomy 21 in one monochorionic pregnancy and in three dichorionic pregnancies but, in all three cases, the positive result concerned only one of the two fetuses. In single pregnancies, the rate of false positives for trisomy 18 was $0.27 \%$, while for Down syndrome the rate would have been $5.0 \%$ if all the fetuses that were at risk and whose karyotype is still unknown did not have T21. However, if some of these fetuses were affected by $\mathrm{T} 21$, the rate of false positives would be lower than $5.0 \%$. With regard to Edwards syndrome, the rate of false positives was rather low, and the only fetus that was affected by the syndrome was detected through maternal serum. The same alterations were found in fetuses with T18 where the presence of T21 can, in some cases, cause the test to indicate a higher risk of T18. Only two cases of prothrombotic risk were detected (Table 6).

\section{Discussion}

Thalassemia includes a heterogeneous group of conditions sharing defective, reduced, or absent synthesis of one of the

Table 4 Phoresis of total hemoglobin and hemoglobin fractions in the various periods. Presence of subjects with multiple pathological variants, both elevated, with alpha/beta chains $(\mathrm{T})$

\begin{tabular}{|c|c|c|c|c|c|c|c|c|c|c|}
\hline Year & Total Hb & HbF $>1.5 \%$ & Hb A2 > 3.2\% & $\mathrm{HbF}+\mathrm{A} 2$ & HbS & $\mathrm{HbC}$ & HbS + T & $\mathrm{HbC}+\mathrm{T}$ & $\mathrm{HbS}+\mathrm{C}$ & $\mathrm{HbE}$ \\
\hline \multirow[t]{2}{*}{$1975-76$} & 504 & 76 & 147 & 21 & 0 & 0 & 0 & 0 & 0 & 0 \\
\hline & & $15.08 \%$ & $29.16 \%$ & $4.16 \%$ & & & & & & \\
\hline \multirow[t]{2}{*}{$1986-87$} & 556 & 52 & 82 & 18 & 2 & 0 & 0 & 0 & 0 & 0 \\
\hline & & $9.35 \%$ & $14.75 \%$ & $3.24 \%$ & $0.36 \%$ & & & & & \\
\hline \multirow[t]{2}{*}{$1995-96$} & 500 & 14 & 106 & 5 & 4 & 2 & 2 & 0 & 0 & 0 \\
\hline & & $2.80 \%$ & $21.2 \%$ & $1.00 \%$ & $0.80 \%$ & $0.40 \%$ & $0.40 \%$ & & & \\
\hline \multirow[t]{2}{*}{2009} & 774 & 96 & 212 & 52 & 44 & 6 & 28 & 6 & 4 & 2 \\
\hline & & $12.4 \%$ & $27.4 \%$ & $6.72 \%$ & $5.68 \%$ & $0.78 \%$ & $3.61 \%$ & $0.78 \%$ & $0.52 \%$ & $0.26 \%$ \\
\hline
\end{tabular}

Abbreviation: $\mathrm{Hb}$, hemoglobin. 
Table 5 Phoresis of total hemoglobin and hemoglobin fractions according to area of origin. Presence of subjects with multiple pathological variants (2009), with/without thalassemia fractions $(T)$

\begin{tabular}{|c|c|c|c|c|c|c|c|c|c|c|c|}
\hline Origin & Total Hb & $\begin{array}{l}\text { Pathological } \\
\mathrm{Hb}\end{array}$ & $\begin{array}{l}\mathrm{HbF}> \\
1.5 \%\end{array}$ & $\begin{array}{l}\text { Hb A2 > } \\
3.2 \%\end{array}$ & $\begin{array}{l}\mathrm{HbF}+ \\
\mathrm{A} 2\end{array}$ & HbS & $\mathrm{HbC}$ & $\begin{array}{l}\text { HbS + } \\
\text { HbT }\end{array}$ & $\begin{array}{l}\mathrm{HbC}+ \\
\mathrm{HbT}\end{array}$ & $\begin{array}{l}\mathrm{HbS}+ \\
\mathrm{HbC}\end{array}$ & HbE \\
\hline \multirow[t]{2}{*}{ Africa } & 28 & 12 & 10 & 8 & 6 & 12 & & 6 & 0 & 0 & 0 \\
\hline & & $42.86 \%$ & $37.71 \%$ & $28.5 \%$ & $21.43 \%$ & $42.86 \%$ & & $21.43 \%$ & & & \\
\hline \multirow[t]{2}{*}{ Asia } & 74 & 32 & 24 & 24 & $|6+2|$ & 10 & 2 & 8 & 2 & 0 & 2 \\
\hline & & $43.24 \%$ & $32.43 \%$ & $32.4 \%$ & $62 \%$ & $13.51 \%$ & $2.70 \%$ & $10.81 \%$ & $2.70 \%$ & & $0.26 \%$ \\
\hline Latin & 30 & 20 & 10 & 18 & 12 & 18 & & 12 & 0 & 0 & 0 \\
\hline American & & $66.66 \%$ & $33.33 \%$ & $60.0 \%$ & $40.00 \%$ & $60.00 \%$ & & $40.00 \%$ & & & \\
\hline East & 64 & 18 & 4 & 16 & 2 & 0 & 0 & 0 & 0 & 0 & 0 \\
\hline Caucasian & & $28.13 \%$ & $6.25 \%$ & $25.0 \%$ & $3.13 \%$ & & & & & & \\
\hline West & 578 & 176 & 48 & 146 & 16 & 4 & 4 & 2 & 4 & 4 & 0 \\
\hline Caucasian & & $30.45 \%$ & $8.30 \%$ & $25.2 \%$ & $2.77 \%$ & $0.70 \%$ & $0.70 \%$ & $0.35 \%$ & $0.70 \%$ & $0.70 \%$ & \\
\hline
\end{tabular}

Abbreviation: $\mathrm{Hb}$, hemoglobin

globin chains of hemoglobin. Although the province of Trieste has never been typically characterized by thalassemia, the trait frequency has particularly increased following immigration from areas with a high incidence of thalassemia, especially Istria and Sardinia during the 1950s and 1960s. The 9801 cases examined by Molaro in FVG between 1978 and 1992 (3212 in the province of Trieste, 3010 in the province of Udine, 2990 in the province of Pordenone, and 589 in the province of Gorizia) suggested a prevalence of the alpha thalassemia trait $(0.26 \%)$ and individual hemoglobin $\mathrm{S}$ and $\mathrm{C}$ diseases. The current data show a new rise of major thalassemia (6.72\%) and a significant presence of hemoglobin $\mathrm{S}(5.68 \%)$, in addition to a more limited percentage of hemoglobin $\mathrm{C}$ and hemoglobin E. A comparison with the recent past, despite the limited percentage, showed no inconsistency with the current data, and no particular prevalence or incidence of hematological diseases. Still pending are the questions related to medical and nursing training in transfusion centers and information given to foreigners (often requiring the presence of a cultural mediator). The purpose of screening has changed, focusing

Table 6 Tests with high risk for thrombosis. The analyzed samples were negative or uncertain for IgE and positive for IgM

\begin{tabular}{|c|c|c|c|c|}
\hline & \multicolumn{4}{|c|}{ Samples } \\
\hline & \multicolumn{2}{|l|}{ 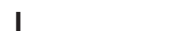 } & \multicolumn{2}{|l|}{2} \\
\hline & IgG & $\lg M$ & IgG & IgM \\
\hline \multicolumn{5}{|l|}{ Antigens } \\
\hline$\beta 2 \mathrm{GPI}$ & Neg & Neg & Neg & Un \\
\hline Cardiolipin + $\beta 2$ GPI & Un & Un & $\mathrm{Neg}$ & Pos \\
\hline Phosphatidyl serine $+\beta 2 \mathrm{GPI}$ & Neg & Pos & Neg & Pos \\
\hline Phosphatidyl inositol $+\beta 2 \mathrm{GPI}$ & Neg & Un & Neg & Pos \\
\hline Phosphatidic acid + $\beta 2 \mathrm{GPI}$ & Neg & Un & Neg & Pos \\
\hline $\operatorname{Mix}+\beta 2 \mathrm{GPI}$ & Un & Pos & Neg & Pos \\
\hline Mix without $\beta 2 \mathrm{GPI}$ & Neg & Pos & Neg & Pos \\
\hline
\end{tabular}

Abbreviations: Neg, negative; Un, uncertain; Pos, positive; $\beta 2 \mathrm{GPI}$, beta2glycoprotein. not only on thalassemia but also on the prevention of other hereditary anemias, so there is a greater need for planning when it comes to blood donation schemes for non-European Union women. ${ }^{4,5}$ Study of the tests for the collection of cord blood is being enriched by data from legally compulsory tests as well as by essential elements for setting up a "universal data bank".

Against such a background, the training of transfusion physicians in the field of diagnostic blood tests has to take into account and respect the cultural, social, and religious plurality of the different populations, in addition to having the necessary scientific knowledge and accuracy that comes from experience.

With regard to screening for fetal defects and associated prothrombotic risk, on the basis of the data obtained in this study (rate of false positives, ability of detection, appropriateness of reference medians), the so-called combined test must be recommended for all pregnancies in mothers over 37 years of age, and it must be borne in mind that test performance is worse in twin pregnancies. ${ }^{6,7}$ With regard to the associated prothrombotic risk, this study does not show any significant difference between European Union and non-European Union women in the presence of antiphospholipid antibodies. However, in the group studied, considering the different antigens separately, all the tests were negative for IgG antibodies and the tests were positive for IgM in only two non-Caucasian women with medically treated dichorionic pregnancies, and in correlation with the risk. ${ }^{8,9}$

\section{Conclusion}

From the social point of view, the hemoglobin percentages found do not indicate a problem concerning blood donation. However, due to the increased number of sickle cell disease cases (having a single mutation of the beta-globin gene), 
particular attention should be paid to the transfusion of non-European Union patients with more severe conditions requiring regular transfusions for frequent hospitalization and surgery. In these cases, either molecular technology should be applied in order to best avoid alloimmunization or, in the light of the available resources and frequency, screening protocols should be set up for preventive purposes, as well as the identification of selected donors and prophylactic antigen matches.

This study has also shown that, in FVG, only 3\% of non-European Union women (versus 70\% European Union citizens) are aware of and avail themselves of bitest screening, This is of concern because the literature shows that Down and Edwards syndromes are more frequent in non-European than in European populations. ${ }^{10}$

Education, either public or private, through voluntary associations may contribute to solving the problem in terms of training and organization of blood donations and biochemical screening in pregnancies for non-European Union women arriving in northern Italy and neighboring areas from Africa, Asia, Latin America, and eastern Europe. ${ }^{10-15}$

\section{Acknowledgment}

The authors extend their thanks to Mrs Sarah Tripepi for her work.

\section{Disclosure}

The authors report no conflicts of interest in this work.

\section{References}

1. Boileau A. Immigration. ISTAT. Foreign in FVG 2009. Available from: http//www.il giornaledel Friuli.net/. Accessed August 13, 2010.

2. Lippi G, Mortagnana M, Danese E, et al. Frequency and type of newly diagnosed haemoglobin variants in Northern Italy. Blood Transfus. 2010;8:307-308.
3. Schuchter K, Hafner E, Stangl G, Metzenbauer M, Hofinger D, Philipp K. The first trimester combined test for the detection of Down syndrome pregnancies in 4939 unselected pregnancies. Prenat Diagn. 2002;22:211-215.

4. King K, Sue S. Transfusion management of patients with sickle cell disease: The continuing dilemma. Transfusion. 2010;50:2-4.

5. De Montalembert M. Use of hydroxyurea from childhood to adult age in sickle cell disease: Semen analysis. Haematologica. 2008;93:e67.

6. Soergel P, Pruggmayer M, Schwerdtfeger R, Muhlhaus K, Scharf A. Screening for trisomy 21 with maternal age, foetal nuchal translucency and maternal serum biochemistry at 11-14 weeks: A regional experience from Germany. Fetal Diagn Ther. 2006;21:264-268.

7. Von Scheven E, Athreya BH, Rose CD, Goldsmith DP, Morton L. Clinical characteristics of antiphospholipid antibody syndrome in children. J Pediatr. 1996;129:339-345.

8. Lee EY, Lee CK, Lee TH, et al. Does the anti-beta2 glycoprotein I antibody provide additional information in patients with thrombosis? Thromb Res. 2003;111:29-32.

9. Levine JS, Ware Branch D, Rauch J. The antiphospholipid syndrome. N Engl J Med. 2002;346:752-763.

10. Muccinelli E, Dall'Amico DC, Bollati C, et al. Alpha-fetoprotein levels in mid trimester pregnancy. Ligand Assay. 2009:14(2).

11. Xie Z, Lu S, Zhu Y, et al. Second-trimester maternal serum free-beta-human chorionic gonadotropin and alpha-fetoprotein levels in normal twin and singleton pregnancies: A report of local Chinese population. Prenatal Diagn. 2008;28:735-738.

12. Streetly A, Latinovic R, Henthorn J. Positive screening and carrier results for the England-wide universal newborn sickle cell screening programme by ethnicity and area for 2005-07. J Clin Pathol. 2010;63:626-629.

13. Peters M, Fijnvandraat K, van den Tweel XW, et al. One-third of the new paediatric patients with sickle cell disease in The Netherlands are immigrants and do not benefit from neonatal screening. Arch Dis Child. 2010;95:822-825.

14. Molaro G. Study of predominance of alfa-thalassemia in Friuli Venezia Giulia region. Blood Transfus. 1993;38:167-170.

15. Donato M, Borin E, Bevacqua G, D’Ottavio G. Biochemical screenings in twin medically treated assessment of trisomy and prothrombotic risk. Minerva Ginecol. 2008;60:263-264.
Risk Management and Healthcare Policy

\section{Publish your work in this journal}

Risk Management and Healthcare Policy is an international, peerreviewed, open access journal focusing on all aspects of public health, policy, and preventative measures to promote good health and improve morbidity and mortality in the population. The journal welcomes submitted papers covering original research, basic science, clinical \& epidemio-

\section{Dovepress}

logical studies, reviews and evaluations, guidelines, expert opinion and commentary, case reports and extended reports. The manuscript management system is completely online and includes a very quick and fair peer-review system, which is all easy to use. Visit http://www.dovepress. com/testimonials.php to read real quotes from published authors. 